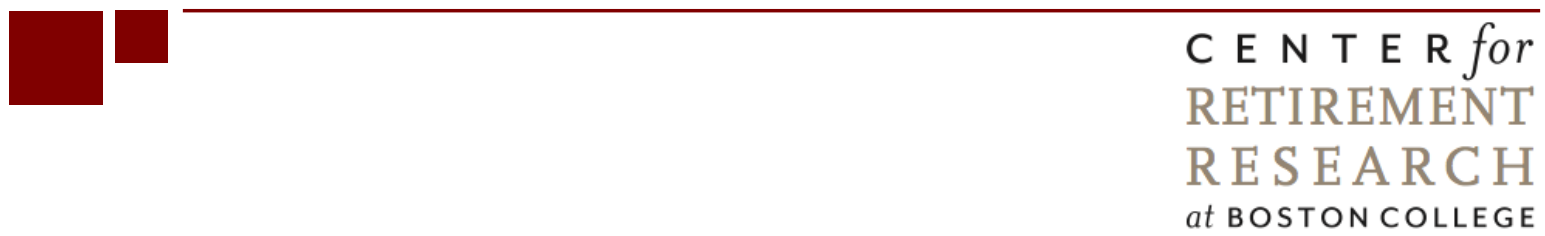

\title{
USING PARTICIPANT DATA TO IMPROVE TARGET DATE FUND ALLOCATIONS
}

\author{
Zhenyu Li and Anthony Webb \\ CRR WP 2012-20 \\ Submitted: September 2012 \\ Released: September 2012
Center for Retirement Research at Boston College
Hovey House
140 Commonwealth Avenue
Chestnut Hill, MA 02467
Tel: 617-552-1762 Fax: 617-552-0191
http://crr.bc.edu

Zhenyu $\mathrm{Li}$ is a research associate at the Center for Retirement Research at Boston College (CRR). Anthony Webb is a research economist at the CRR. The research reported herein was supported by Charles Schwab \& Co., Inc. The findings and conclusions expressed are solely those of the authors and do not represent the opinions or policy of Charles Schwab \& Co., Inc. or the CRR.

(C) 2012, by Zhenyu Li and Anthony Webb. All rights reserved. Short sections of text, not to exceed two paragraphs, may be quoted without explicit permission provided that full credit, including (C) notice, is given to the source. 


\section{About the Center for Retirement Research}

The Center for Retirement Research at Boston College, part of a consortium that includes parallel centers at the University of Michigan and the National Bureau of Economic Research, was established in 1998 through a grant from the Social Security Administration. The Center's mission is to produce first-class research and forge a strong link between the academic community and decision-makers in the public and private sectors around an issue of critical importance to the nation's future. To achieve this mission, the Center sponsors a wide variety of research projects, transmits new findings to a broad audience, trains new scholars, and broadens access to valuable data sources.

Center for Retirement Research at Boston College

Hovey House

140 Commonwealth Avenue

Chestnut Hill, MA 02467

phone: 617-552-1762 fax: 617-552-0191

e-mail: crr@bc.edu

crr.bc.edu

Affiliated Institutions:

The Brookings Institution

Massachusetts Institute of Technology

Syracuse University

Urban Institute 


\begin{abstract}
Economic theory says that participants in 401(k) plans should gradually rebalance their portfolios away from stocks and toward less risky bonds as they approach retirement. Conventional target date funds attempt to do so by automatically rebalancing the household's portfolio periodically, but they take account of only one aspect of the individual: his expected retirement age. This paper investigates whether plan providers could improve on this "one-size-fits-all” approach by making use of information that is known to the employer, namely each employee's income, 401(k) balance, and saving rate. Using a stochastic dynamic optimization model, incorporating both labor- and financial-market risk, it calculates the compensation a household following an optimal portfolio allocation would require for adopting three alternatives: a typical, a “one-size-fits-all,” or a "semi-personalized” portfolio allocation.
\end{abstract}




\section{Introduction}

Economic theory says that participants in 401(k) plans should gradually rebalance their portfolios away from stocks and toward less risky bonds as they approach retirement. The rationale is that at younger ages households hold a substantial portion of their wealth in the expected present value of their remaining lifetime earnings, which is generally viewed as a relatively low-risk asset, so they should hold much of their financial assets in high-risk, high-return stocks. As households approach retirement, the value of the earnings asset declines, so they should compensate by rebalancing their investment portfolios away from stocks and into bonds. ${ }^{1}$

Many households fail to rebalance their portfolios as they age, reflecting both inertia and a lack of investment skills. As a result, 401(k) plans offer life-cycle or target date funds that automatically rebalance the household's portfolio with age. Conventional target date funds take into account only one aspect of an individual: the employee's expected retirement date. In fact, the plan provider knows additional information about the individual, including his earnings, the balance in his 401(k) account, and his saving rate. Using a stochastic dynamic optimization model of household consumption and portfolio allocation, this paper compares how much a conventional, "one-size-fits-all” target date fund improves the outcome relative to what individuals would do on their own and how much taking into account the additional information improves the outcome compared to the one-size-fits-all target date fund.

This paper proceeds as follows. The first section reviews previous research. The second section describes the household's optimization problem and establishes the benchmark - expected discounted lifetime utility from an optimal investment strategy - against which each 401(k) investment option is compared. The third section describes the horse race in which the outcome for each of the three allocation approaches is compared to the benchmark. The fourth section considers how the ranking of these strategies might be affected if the one-size-fits-all and semi-personalized portfolio allocations were based upon incorrect estimates of the household's level of risk aversion. It also suggests two additional adjustments - basing portfolios on estimated household characteristics rather than relying solely on participant data. and taking into account the riskiness of the participant's earnings - that may bring outcomes closer to the optimal. The final section concludes that a target date fund is a better strategy than leaving the household on its own and that adding information to the one-size-fits-all target date fund can bring the outcome even closer to the optimal for the great majority of households.

\section{Previous Research}

Economists typically calculate optimal portfolio allocation under the assumption that households maximize expected utility over their lifetimes. A substantial literature considers optimal portfolio

\footnotetext{
${ }^{1}$ Jagannathan and Kocherlakota (1996).
} 
allocation over the life cycle, and how optimal portfolio allocation might be affected by labor income uncertainty. ${ }^{2}$ This literature shows that, in the absence of labor income uncertainty, households should gradually rebalance their portfolios away from risky stocks and into lower-risk bonds as they age. The reason is that, at younger ages, most of the household's wealth is in the form of relatively low-risk human capital. This asset has bond-like investment characteristics and substitutes for bonds in the household's portfolio. As the household approaches retirement, the value of remaining lifetime human capital declines and the value of financial assets increases, so the household optimally rebalances in favor of bonds. When labor income is risky, its investment characteristics become less bond-like and more stocklike. Maurer, Mitchell, and Rogalla (2010) show that when labor market earnings are risky, the optimal response is to increase savings and reduce the portfolio share allocated to risky assets. A positive correlation between labor market earnings and stock returns accentuates the above effects.

The above authors also assume a fixed retirement age of 65 . If households are able and willing to respond to financial market shocks by delaying retirement, they may optimally choose to invest more aggressively. We observe considerable heterogeneity in retirement ages, reflecting health shocks and differences in preferences and in labor market realizations. It is less clear to what extent households are able and willing to adjust their retirement ages in response to financial market shocks. Gustman and Steinmeier (2002), Coronado and Perozek (2003), and Sevak (2002) show that the stock market boom of the 1990s had a modest but significant effect on the age of retirement. Using preference parameters from Gustman and Steinmeier (2005), Gustman, Steinmeier, and Tabatabai (2009) estimate that the 2007-2009 stock market crash may lead to an increase in the average age of retirement of only a few months among those who did not suffer involuntary job loss. This small effect reflects small average 401(k) balances and highly conservative investment allocations of non-pension financial assets. One might expect larger effects among households who had accumulated more significant amounts of financial wealth. But the evidence suggests that the disutility of work increases fairly rapidly with age and declines in health, so that even households suffering large wealth shocks may be reluctant to work many more years. If so, delaying retirement may provide only limited protection against financial market shocks.

The recommendations of financial planners generally accord with the predictions of economic theory. Financial planners do not model optimal portfolio allocations within an expected utility maximizing framework, but instead emphasize the household's willingness and capacity to bear risk. Both capacity and willingness will be influenced by the factors discussed above.

\footnotetext{
${ }^{2}$ Studies include Bodie, Merton, and Samuelson (1992); Bodie, Detemple, Otruba, and Walter (2004); Campbell and Viceira (2001); Heaton and Lucas (1997); Polkovnichenko (2007); and Viceira (2001).
} 


\section{The Benchmark}

Comparing alternative approaches to asset allocation requires a benchmark. The approach taken in this study is to use numerical optimization techniques to model optimal savings and asset allocation. We assume a married-couple household with a constant relative risk aversion (CRRA) utility function of the following form:

$$
U_{m}\left(C_{t}^{m}, C_{t}^{f}\right)=\frac{\left(C_{t}^{m}+\lambda C_{t}^{f}\right)^{1-\gamma}}{1-\gamma}, U_{f}\left(C_{t}^{f}, C_{t}^{m}\right)=\frac{\left(C_{t}^{f}+\lambda C_{t}^{m}\right)^{1-\gamma}}{1-\gamma}
$$

where $\lambda$ measures the jointness of consumption; $C_{t}^{m}, C_{t}^{f}$ denote the consumption of the husband and wife at time $t$; and $\gamma$ is the coefficient of risk aversion. When $\lambda$ equals one, all consumption is joint. When $\lambda$ equals zero, none of the household's consumption is joint. We assume that $\lambda$ equals 0.5 . Chiappori and Paiella (2011) argue that a CRRA utility function characterizes the risk preferences of typical households.

The household's objective is to maximize:

$$
\sum_{t=22}^{T} \sum_{m=1}^{m=3} B^{t-22} \rho_{m, t} E_{t} U\left(C_{t . m}\right)
$$

where $m$ is marital status (married, surviving male, or surviving female); $\beta$ is a rate of time preference, assumed to be $0.97 ; \rho_{m . t}$ is the probability of being in marital status $m$ at time $t$; and $C_{t, m}$ is consumption at time $t$ in marital state $m .^{3}$

The household faces the following budget and non-negativity constraints:

$$
\begin{gathered}
W_{t+1}=\left(W_{t}+I_{t}+S S_{t}-C_{t}-\tau_{t}-F I C A_{t}\right)\left(1+R_{p, t+1}\right) \\
W_{t} \geq 0 \text { for all } t
\end{gathered}
$$

where $W$ is wealth, $I$ is labor income; $S S$ is Social Security benefit; $\tau$ is federal income tax; FICA is the Social Security tax; and $R_{p, t+1}$ is the portfolio return at time $t+1$. All savings are held in tax-deferred accounts. This approach reduces the number of state variables and enables us to abstract from the asset location decision. Most moderate-income households hold only small amounts of wealth outside of their

\footnotetext{
${ }^{3}$ We assume that the husband and wife have population average mortality for the 1970 birth cohort.
} 
401(k)/IRA accounts. We model Social Security benefits as a non-linear function of lifetime earnings. ${ }^{4}$

This non-linearity results in households with low lifetime earnings receiving higher rates of return on their contributions, providing partial insurance against bad labor market outcomes. This insurance may affect the optimal allocation of financial assets. We carefully model the taxation of Social Security benefits. $^{5}$

The household faces uncertainty in both the labor and capital markets. We assume that households can invest in both a risk-free bond, yielding a 3-percent real interest rate, and risky stocks, with real returns log normally distributed with a mean of 6.5 percent and standard deviation of 20 percent. $^{6}$

We model labor income uncertainty using model and parameter values in Scholz, Seshadri, and Khitatrakun (2006). They assume that the household model of log earnings is;

$$
\begin{gathered}
\log e_{j}=\alpha^{i}+\beta_{1} A G E_{j}+\beta_{2} A G E_{j}^{2}+u_{j} \\
u_{j}=\rho u_{j-1}+\varepsilon_{j}
\end{gathered}
$$

where $e_{j}$ is the observed earnings of the household $i$ at age $j$ in 1992 dollars; $\alpha^{i}$ is the household specific constant; $A G E_{j}$ is the age of the head of the household; $u_{j}$ is an $\mathrm{AR}(1)$ error term of the earnings

\footnotetext{
${ }^{4}$ The Social Security retired worker benefit payable at the Full Retirement Age is a non-linear function of Average Indexed Monthly Earnings (AIME). AIME is the average of the highest 35 years' earnings, with earnings for years prior to the year in which the individual attained age 60 being indexed to the National Average Wage Index. Reflecting both the limits of computational feasibility and the focus of their research, Mitchell, Maurer, and Rogalla (2010) modeled Social Security benefits as a function of final year earnings, instead of average lifetime earnings. Their approach will likely overstate the riskiness of Social Security and potentially yield biased estimates of optimal portfolio allocations at younger ages. The magnitude of this bias is unclear ex-ante. We follow Benitez-Silva et al. (2007) and model benefits as a function of indexed lifetime earnings, making an adjustment to reflect the fact that the average of the highest 35 years earnings will be somewhat higher.

${ }^{5}$ The taxation treatment of Social Security benefits is as follows. First, the household's "combined income" is calculated. This equals regular taxable income plus 50 percent of Social Security income. The amount of Social Security income that is taxable is the minimum of three tests: (1) 50 percent of combined income over the first threshold ( $\$ 25,000$ for singles and $\$ 32,000$ for married couples), plus 35 percent of combined income over the second threshold ( $\$ 34,000$ for singles and $\$ 44,000$ for married couples); (2) 50 percent of benefits plus 85 percent of combined income over the second threshold; and (3) 85 percent of benefits. See Internal Revenue Service (2012). ${ }^{6}$ In reality, the real yield on long-dated bonds fluctuates considerably, while there is also considerable evidence that stock returns exhibit mean reversion. Campbell and Viceira (2002) show that long-term bonds are the true risk-free asset for long-term investors because they provide a guaranteed income. If stock returns exhibit mean reversion, then the optimal equity allocation should reflect whether expected returns are high or low relative to the long-run average. But incorporating the above features would greatly complicate our model without yielding any important additional insights.
} 
equation; and $\varepsilon_{j}$ is a mean zero i.i.d. normally distributed error term. They report parameter estimates in their Appendix Table A1. ${ }^{7}$

We assume coefficients of risk aversion of two and five. These figures rest within the range of 2 to 10 reported in the literature, depending in part on whether the estimates are derived from portfolio theory, purchases of insurance, economic experiments, or preferences over lotteries (Chetty 2003). The retirement age is assumed to be 65 .

Our model abstracts from many characteristics that might affect portfolio allocation. In particular, we ignore the house, which is both a risky asset and a hedge against uncertain rental costs. We ignore medical costs and health shocks. This decision reflects computational constraints. A financial planner would likely consider the above factors when recommending portfolio allocations. It is unclear whether the financial planner's recommendations, which are based on his judgment and experience, perhaps supplemented by the results of Monte-Carlo simulations, yield better outcomes than those produced by our mathematical model of optimizing behavior.

Once the model is constructed, the first step is to estimate it with fully optimizing behavior for the typical household. In each period, starting at age 22 when the household has zero wealth, it chooses how much to consume and how to allocate its portfolio between risky stocks and a risk-free bond. The results vary by the household's degree of risk aversion and the level and the uncertainty surrounding its earnings.

\section{The Horse Race}

The model is then re-estimated under three scenarios, in which the household is constrained to invest in: 1) the portfolio held by the typical household; 2) a one-size-fits-all target date fund; and 3) a semi-personalized target date fund that takes into account the individual's earnings, 401(k) balance, and saving rate. In each case, the model yields an expected utility of lifetime consumption, which can be compared to the utility of the consumption produced by the optimal portfolio. In our initial analyses, we assume that the semi-personalized and one-size-fits-all portfolios are constructed using the same coefficient of risk aversion used to construct the optimal portfolio. We later relax this assumption and consider the consequences of constructing target date portfolio allocations using plausible but incorrect estimates of the household's coefficient of risk aversion. The measures used for comparing the three scenarios to fully optimizing behavior are the percentage increase in annual salary that the household

\footnotetext{
${ }^{7}$ The model abstracts from the risk of unemployment. Incorporating the risk of unemployment would greatly complicate the analysis because we would need to both model this source of risk and incorporate social insurance programs and labor supply responses within the family.
} 
would require to be indifferent between the specified portfolio and the optimal portfolio, and the amount to which that increase would grow by age 65 at the risk-free rate. ${ }^{8}$

The key fact to keep in mind is that the benchmark results are for the household and based on the household's information, but the portfolios for the one-size-fits-all and the semi-personalized alternatives in the horse race described below are based on information about the participant, the only information the plan provider has available.

The Typical Portfolio. For the first horse in this race, the household is given a typical portfolio allocation and is allowed to select an optimal saving rate, given this allocation. The results are used to calculate the percentage salary increase that the household would require to be indifferent between the typical and the optimal portfolio allocation, and the average amount that this percentage of salary would grow to by age 65 . Households adopt widely differing portfolio allocations, and we acknowledge that these portfolio allocations may reflect optimizing behavior, given differing preferences, risk factors, and endowments. If so, then switching households into any kind of target date fund would reduce well-being, except in the rare case in which the target date fund exactly matched the household's preferences. The minority of households that is financially literate or has access to financial planning advice is, of course, free to override the target date fund defaults.

Many studies have documented extremely low levels of financial literacy (Lusardi and Mitchell, 2011; Lusardi, 2012), suggesting it is unlikely that portfolio allocations will typically be chosen as the result of optimizing behavior. Huberman and Jiang (2006) show that 401(k) plan participants typically adopt a 1/n heuristic. Mitchell et al. (2006) show that households rarely rebalance their portfolios. Our analysis of the Survey of Consumer Finances (SCF) data supports this view. Households in the SCF are asked about the amount of financial risk they are willing to take when saving or making investments. Although we find a statistically significant correlation between responses and portfolio allocations, it is much smaller than would be predicted from an intertemporal optimization model incorporating plausible variations in levels of risk-aversion. The absence of a strong relationship is consistent with a minority of financially literate households attempting to optimize their portfolio allocations based on their risk preferences, while remaining households either misunderstand the risk characteristics of investments or adopt some heuristic. ${ }^{9}$

\footnotetext{
${ }^{8}$ This approach is analogous to the annuity equivalent wealth calculation made in the annuitization literature (Brown and Poterba, 2000), the percentage increase in age 65 wealth that would leave the household indifferent between an actuarially fair annuity and an optimal decumulation of unannuitized wealth. We choose age 65 in preference to age 22 because liquidity constraints would prevent the latter amount from ever being negative.

${ }^{9}$ This relationship holds both in simple correlations and in econometric models in which we control for financial assets, income, age, and 401(k) eligibility.
} 
Reflecting the above literature, we assume that the portfolio allocations of many households are uncorrelated with risk preferences and that these households do not rebalance their portfolios with age or in response to financial or labor market shocks. Instead, we assume that they adopt age-invariant allocations of 401(k) contributions, the allocations chosen so that, averaged over Monte-Carlo simulations, they result in the average age 55-64 portfolio allocations observed in the 2007 SCF for households in their income tercile.

The analysis includes three prototypical households with different levels of earnings. Our base case is a two-earner, college-educated couple, with an earnings process estimated by Scholz, Seshadri, and Khitatrakun (2006) for that household type. Their model predicts average earnings for this household type of \$91,000 in 2012 dollars. We also consider low and high earners, who earn half and double the above amounts but face the same degree of labor income uncertainty.

Assuming a coefficient of risk aversion of five, and given the baseline assumptions, the household with average income would require a 0.79 -percent increase in salary as compensation for investing in the typical portfolio compared to the optimal strategy. The above number may at first appear small but, if it were set aside and invested each year at the risk-free rate, it would grow to $\$ 60,000$ by age 65 (see Table 1 top panel). A high-earner household would require a similar percentage increase in salary (0.80 percent), but the cumulative amount would equal \$122,000 at age 65 , reflecting the household's higher lifetime earnings. At a coefficient of risk aversion of two, the required compensation is substantially greater because the typical portfolio is highly conservative. A household with average income would require a 3.95 percent increase in salary, which would grow to $\$ 300,000$ by age 65 .

A One-Size-Fits-All Target Date Fund. The second horse is a one-size-fits-all target date fund portfolio. According to the life-cycle model, households should gradually rebalance from stocks to bonds as they age, reflecting the declining value of their human capital. The plan provider designs a fund that gradually reduces the share of equities in the portfolio. The portfolio will be derived from a model similar to the one discussed above, which serves as a benchmark in this study, and would be - by design optimal for the average household, had the allocation been based on household information. However, as discussed above, the plan provider only knows the earnings of the individual, so the portfolio allocation is somewhat suboptimal even for the average household.

The percentage increases in salary and dollar amounts at age 65 that households investing in the optimal portfolio would require as compensation for investing in the one-size-fits-all fund are reported in the middle panel of Table 1.

Assuming a coefficient of risk aversion of five, and given the baseline assumptions, the household with average income would require a 0.50 -percent increase in salary for investing in the one- 
size-fits-all portfolio compared to the optimal strategy. A comparison of the numbers in the top panel with the corresponding number in the middle panel shows that, in all the cases studied, the one-size-fitsall portfolio is closer to the optimal than the typical portfolio, reflecting the benefits of adjusting portfolio allocation over the life cycle.

A Semi-Personalized Target Date Fund. The third horse is a semi-personalized target date fund portfolio that reflects information known to the employer, namely the participant's earnings, saving rate and plan balance. Subject to the important caveat referred to above, namely that the model used to construct the semi-personalized portfolio incorporates all risk factors and correctly reflects the household's risk tolerance, the semi-personalized strategy would be optimal at each income level if the allocation had been based on the household's information. Given that it reflects only the participant's earnings, 401(k) assets, and saving rate, households remain in a suboptimal position and require some compensation. For a household that has precisely the average income, by definition, the semipersonalized portfolio performs just as well as the one-size-fits-all target date fund.

The percentage increases in salary and dollar amounts at age 65 that households investing in the optimal portfolio would require as compensation for investing in the semi-personalized fund are reported in the bottom panel of Table 1. Assuming a coefficient of risk aversion of five, and given the baseline assumptions, the household with twice the average income would require a 0.35 -percent increase in salary for investing in the semi-personalized compared to the optimal strategy. A comparison of the numbers in the middle panel with the corresponding numbers in the bottom panel shows that in all the cases studied the semi-personalized portfolio is at least as close to optimal as the one-size-fits-all portfolio, reflecting the benefits of making use of more information known to the employer.

\section{Improving the Results}

In this section, we consider how the ranking of the above strategies might be affected if the portfolio allocations of the one-size-fits-all and semi-personalized plans were based on incorrect estimates of household risk preferences. We also consider how the performance of the semi-personalized plan could be improved by basing asset allocation on estimated household information rather than simply on what is known about the participant, and by taking earnings uncertainty explicitly into account.

Using incorrect estimates of risk preferences. A potential concern with both the semipersonalized and one-size-fits-all portfolios is that they may be based on incorrect estimates of households' risk preferences. The two lower panels in Table 2 report the percentage increases in salary and dollar amounts that households would require as compensation for investing in a one-size-fits-all or 
semi-personalized portfolio that incorrectly assumes their coefficient of risk aversion is two, when it is really five, or assumes that it is five when it is really two.

A typical household with a coefficient of risk aversion of two would require compensation of 0.33 percent of salary for being placed in a one-size-fits-all portfolio designed to be optimal for the typical individual with a coefficient of risk aversion of five. This result compares with the 0.15 percent of salary compensation it would require for being placed in a one-size fits-all fund designed to be optimal for the typical individual with a coefficient of risk aversion of two. When the household with a coefficient of risk aversion of five is placed in a fund designed to be optimal for the typical individual with a coefficient of risk aversion of two, the required compensation is even greater, at 0.51 percent of salary, compared to 0.50 percent when the fund assumes a correct level of risk aversion. A similar pattern emerges with the semi-personalized portfolio allocation. In all the cases studies, both the one-size-fits-all and semi-personalized portfolio allocations are dramatically superior to the typical portfolio allocation, even when these portfolios are based on incorrect estimates of risk-aversion. Although the imposition of incorrect preference parameters can sometimes result in the semi-customized portfolio allocation performing worse than the one-size-fits-all portfolio, the amounts by which it falls short are, in contrast, small.

But the above calculations also show that if there is heterogeneity in risk preferences and if households are ill-equipped to choose portfolio allocations that reflect their risk preferences, household well-being would be significantly enhanced if plan sponsors elicited those preferences and tailored portfolio allocations accordingly. Counterintuitively, the costs imposed on households of plan sponsors incorrectly assuming that households are risk averse exceed the costs of incorrectly assuming that households are risk tolerant. Risk-tolerant households place a high value on the ability to benefit from the equity premium. Given heterogeneity in risk preferences, plan sponsors that are seeking to minimize the incidence of really inappropriate portfolio allocations and are unable to elicit risk preferences should assume relatively modest coefficients of risk aversion.

Individual versus Household. The calculations in Section 3 assume that the employer observes only the participant's income and 401(k) plan balance but has no information regarding the spouse's income and 401(k) plan balance or the household's non-401(k) financial assets. One solution would be for the plan sponsor to ask the employee for this information. If the employee correctly reports income and accumulated financial assets, the semi-personalized strategy would be optimal at each income level, subject to the important caveat referred to above - namely that the model used to construct the semi-personalized portfolio incorporates all risk factors and correctly reflects the household's risk tolerance. 
But how should the plan sponsor deal with the many employees who would be unlikely to supply this information? One potential solution is to use the SCF or similar data sets to construct an econometric model that could be used to predict the spouse's income and assets based on the participant's income, 401(k) plan balance, age, gender, marital status, and job tenure, all of which is known to the employer. When predicting income, one would first predict whether the spouse is working and then predict the spouse's earnings, conditional on working.

In practice, even the best econometric model will not accurately estimate both income and financial assets. Furthermore, the plan sponsor's goal should not be to incorporate the best possible estimates of household income and assets, but to arrive at estimates that maximize expected utility. Suppose that there is some probability $p$ that the spouse is working. Then the goal should be to maximize:

$$
p E(U)\left|y_{s w}+(1-p) E(U)\right| y_{s n w}
$$

where $y_{s w}$ is the household's income, conditional on the spouse working; and $y_{\text {snw }}$ is the household's income, conditional on the spouse not working.

To gauge our ability to accurately forecast household income, we first estimate the following econometric model for men and women separately:

$$
Y_{i}=f\left(\beta_{0}+\beta_{1} A_{i}+\beta_{2} A_{i}^{2}+\beta_{3} A_{i}^{3}+\beta_{4} Y P_{i}+\beta_{5} P L_{i}+\beta_{6} T_{i}+\beta_{7} T_{i}^{2}+\beta_{8} L H S_{i}+\beta_{9} S C_{i}+\varepsilon_{i}\right)
$$

where the specification of the function $f$ is linear or standard normal, depending on whether we are estimating a probit model with the spouse's labor force participation decision as the dependent variable, or estimating an OLS model, with the log of the spouse's earnings or the log of the household's financial assets exclusive of the participant's 401(k) plan balance as the dependent variable; and where $A_{i}$ denotes age; $Y P_{i}$ the participant's income; $P L_{i}$ the participant's $401(\mathrm{k})$ plan balance; $T_{i}$ the participant's job tenure; and $L H S_{i}$ and $S C_{i}$ and dummies indicating whether the participant has less than a high school education or some college.

Table 3 reports the results of a sample of married 401(k) plan participants, ages 22 to 64, in the 2010 SCF. Among the married men, 88.9 percent are working and 11.1 percent are not working. Among the married women, 67.0 percent are working and 33.0 percent are not working. Although many explanatory variables are statistically significant, our model has limited predictive power, and we can do 
no better than to assume that all spouses are working. When we correctly categorize married women as working, the average over-estimation and under-estimation of the wife's earnings are 16.2 and 18.8 percent, respectively.

Table 4 reports the impact of various types of forecasting errors for married men with average earnings who have a coefficient of risk aversion of five, and who are placed in the semi-personalized portfolio. Although not negligible, the amounts of compensation required, relative to an optimal portfolio are of an order of magnitude smaller than those required for similar households adopting typical portfolios.

Earnings Risk. The optimal portfolio allocation also depends on the riskiness of the household's earnings. Participants who have secure earnings can take on more risk in their 401(k) portfolios than those who face significant earnings uncertainty. Table 5 shows the compensation required for the semipersonalized approach, by earnings level and by degree of earnings uncertainty. As before, the semipersonalized approach is optimal for households with average earnings uncertainty at all income levels. It is close to optimal for those with below-average earnings uncertainty, because their optimal portfolios are similar to that of households with average earnings uncertainty. In contrast, the semi-personalized approach is far from optimal for households with more earnings uncertainty. ${ }^{10}$ These losses could be eliminated by estimating labor-market risk by firm and adjusting the recommended asset allocation accordingly.

\section{Conclusion}

Many households fail to rebalance their 401(k) asset allocations as they age, which is at odds with the guidance provided by economic theory. In response, a large number of 401(k) plans now offer target date funds, which automatically rebalance portfolios. Although it is possible that the wide variation in portfolio allocations represents rational responses to widely differing circumstances and preferences, the behavioral finance literature suggests otherwise. If so, the target date approach is a clear improvement over leaving participants on their own. However, conventional target date funds follow a one-size-fits-all approach that accounts for only one variable: each worker's expected retirement date. We show that a semi-personalized target date fund, which also incorporates a worker's earnings, 401(k) account balance, and saving rate, generally outperforms the one-size-fits-all fund by more closely matching an optimal portfolio. These results can be improved even further by eliciting information on household risk

\footnotetext{
${ }^{10}$ The standard deviation of the earnings shocks of the low-volatility households is defined as zero, and that of the high-volatility households is twice the average. When households do not face any labor income uncertainty, it is optimal to hold slightly more in equities. When they face higher volatility, they optimally hold substantially less in equities.
} 
preferences, by including information on the household, rather than simply the individual participant, and by taking into account the household's earnings uncertainty. 


\section{References}

Bodie, Zvi, Robert C. Merton, and William F. Samuelson. 1992. "Labor Supply Flexibility and Portfolio Allocation in a Life Cycle Model.” Journal of Economic Dynamics and Control 16: 427-449.

Bodie, Zvi, Jérôme B. Detemple, Susanne Otruba, and Stephan Walter. 2004. "Optimal ConsumptionPortfolio Choices and Retirement Planning.” Journal of Economic Dynamics and Control 28: 1115-1148.

Brown, Jeffrey R., and Amy Finkelstein. 2008. "The Interaction of Public and Private Insurance: Medicaid and the Long-Term Care Insurance Market.” American Economic Review 98(3): 10831102.

Campbell, John and Luis Viceira. 2002. “Who Should Buy Long-Term Bonds?” American Economic Review 91(1): 99-127.

Chetty, Raj. 2003. “A New Method of Estimating Risk Aversion.” Working Paper 9,988. Cambridge, MA: National Bureau of Economic Research.

Chiappori, Pierre-Andre and Monica Paiella. 2011. "Relative Risk Aversion is Constant” Evidence from Panel Data.” Journal of the European Economic Association 9(6): 1021-1052.

Coronado, Julia Lynn, and Maria Perozek. 2003. "Wealth Effects and the Consumption of Leisure: Retirement Decisions During the Stock Market Boom of the 1990s.” Board of Governors of the Federal Reserve System, Finance and Economics Discussion Series 2003-20.

Gustman, Alan L., and Thomas L. Steinmeier. 2002. "Retirement and the Stock Market Bubble.” Working Paper No. 9,404. Cambridge, MA: National Bureau of Economic Research.

Gustman, Alan L., and Thomas L. Steinmeier. 2005. "The Social Security Early Entitlement Age in a Structural Model of Retirement and Wealth.” Journal of Public Economics 89(2-3): 441-63.

Gustman, Alan L., Thomas L. Steinmeier, and Nahid Tabatabai. 2009. "What the Stock Market Decline Means for the Financial Security and Retirement Choices of the Near-Retirement Population.” Working Paper No. 15,435. Cambridge, MA: National Bureau of Economic Research.

Heaton, John and Deborah Lucas. 1997. “Market Frictions, Savings and Portfolio Choice.” Macroeconomic Dynamics 1: 76-101.

Huberman, Gur and Wei Jiang. 2006. “Offering Choice in 401(K0 Plans: Equity Exposure and Number of Funds.” Journal of Finance 61(2): 763-801.

Internal Revenue Service. 2012. Social Security and Equivalent Railroad Retirement Benefits. Publication 915. Washington, DC: U.S. Department of the Treasury. Available at: http://www.irs.gov/pub/irspdf/p915.pdf

Lusardi, Annamaria and Olivia S. Mitchell. 2011. "Financial Literacy and Retirement Planning in the United States.” Journal of Pension Economics and Finance 10(4): 509-525.

Lusardi, Annamaria. 2012. “Numeracy, Financial Literacy, and Financial Decision-Making.” Working Paper No. 17,821. Cambridge, MA: National Bureau of Economic Research 
Maurer, Raimond, Olivia S. Mitchell, and Ralph Rogalla. 2010. "The Effect of Uncertain Labor Income and Social Security on Life-Cycle Portfolios.” Working Paper No. 15682. Cambridge, MA: National Bureau of Economic Research.

Mitchell, Olivia S., James M. Poterba, Mark J. Warshawsky, and Jeffrey R. Brown. 1999. "New Evidence on the Money’s Worth of Individual Annuities.” American Economic Review 89(5): 1299-1318.

Munnell, Alicia H., Francesca Golub-Sass, and Dan Muldoon. 2009. “An Update on 401(k) Plans: Insights from the 2007 SCF.” Issue Brief No. 9-5. Chestnut Hill, MA: Center for Retirement Research at Boston College.

Munnell, Alicia H., Natalia Sergeyevna Orlova, and Anthony Webb. 2012. "How Important is Asset Allocation to Financial Security in Retirement.” Working Paper No. 9-5. Chestnut Hill, MA: Center for Retirement Research at Boston College.

Polkovnichenko, Valery. 2007. "Life-Cycle Portfolio Choice with Additive Habit Formation Preferences and Uninsurable Labor Income Risk.” Review of Financial Studies 20: 83-124.

Rubinstein, Mark. 1976. “The Strong Case for the Generalized Logarithmic Utility Model as the Premier Model of Financial Markets.” Journal of Finance 31(551-71).

Scholz, John Karl, Ananth Seshadri, and Surachai Khitatrakun. 2006. “Are Americans Saving “Optimally” for Retirement.” Journal of Political Economy 144: 607-643.

Sevak, Purvi. 2002. Wealth Shocks and Retirement: Evidence from the Nineties.” Working Paper No. 2002-027. Ann Arbor, MI: University of Michigan Retirement Research Center.

Viceira, Luis M. 2001. “Optimal Portfolio Choice for Long-Horizon Investors with Non-Tradable Labor Income.” Journal of Finance 56: 433-470. 
Table 1. Compensation Required for Adopting a Typical, One-Size-Fits-All, or Semi-Personalized Portfolio Allocation

\begin{tabular}{|c|c|c|c|}
\hline & \multicolumn{3}{|c|}{ Income } \\
\hline & Low & Average & High \\
\hline & \multicolumn{3}{|c|}{ Typical portfolio allocation } \\
\hline \multicolumn{4}{|l|}{ CRRA $=2$} \\
\hline Percent of salary & 2.65 & 3.95 & 6.15 \\
\hline Dollars at age 65 & 100,000 & 300,000 & 934,000 \\
\hline \multicolumn{4}{|l|}{$\mathrm{CRRA}=5$} \\
\hline Percent of salary & 0.83 & 0.79 & 0.80 \\
\hline \multirow[t]{2}{*}{ Dollars at age 65} & 31,000 & 60,000 & 122,000 \\
\hline & \multicolumn{3}{|c|}{ One-size-fits-all portfolio } \\
\hline \multicolumn{4}{|l|}{ CRRA = 2} \\
\hline Percent of salary & 0.10 & 0.15 & 0.21 \\
\hline Dollars at age 65 & 4,000 & 11,000 & 32,000 \\
\hline \multicolumn{4}{|l|}{$\mathrm{CRRA}=5$} \\
\hline Percent of salary & 0.45 & 0.50 & 0.50 \\
\hline \multirow[t]{2}{*}{ Dollars at age 65} & 17,000 & 38,000 & 76,000 \\
\hline & \multicolumn{3}{|c|}{ Semi-personalized portfolio } \\
\hline \multicolumn{4}{|l|}{$\mathrm{CRRA}=2$} \\
\hline Percent of salary & 0.11 & 0.15 & 0.11 \\
\hline Dollars at age 65 & 4,000 & 11,000 & 17,000 \\
\hline \multicolumn{4}{|l|}{$\mathrm{CRRA}=5$} \\
\hline Percent of salary & 0.38 & 0.50 & 0.35 \\
\hline Dollars at age 65 & 14,000 & 38,000 & 53,000 \\
\hline
\end{tabular}

Notes: All dollar amounts are in 2011 dollars.

Source: Authors' calculations. 
Table 2. Compensation Required for Adopting a One-Size-Fits-All or Semi-Personalized Portfolio Allocation Based on Incorrect Risk Preferences

\begin{tabular}{|c|c|c|c|}
\hline & \multicolumn{3}{|c|}{ Income } \\
\hline & Low & Average & High \\
\hline & \multicolumn{3}{|c|}{ Typical portfolio allocation (as reported in Table 1) } \\
\hline \multicolumn{4}{|l|}{$\mathrm{CRRA}=2$} \\
\hline Percent of salary & 2.65 & 3.95 & 6.15 \\
\hline \multicolumn{4}{|l|}{$\mathrm{CRRA}=5$} \\
\hline Percent of salary & 0.83 & 0.79 & 0.80 \\
\hline \multirow[t]{2}{*}{ Dollars at age 65} & 31,000 & 60,000 & 122,000 \\
\hline & \multicolumn{3}{|c|}{ One-size-fits-all-portfolio } \\
\hline \multicolumn{4}{|c|}{ CRRA assumed to be 5 but really 2} \\
\hline Percent of salary & 0.34 & 0.33 & 0.34 \\
\hline Dollars at age 65 & 13,000 & 25,000 & 52,000 \\
\hline \multicolumn{4}{|c|}{ CRRA assumed to be 2 but really 5} \\
\hline Percent of salary & 0.48 & 0.51 & 0.55 \\
\hline \multirow[t]{2}{*}{ Dollars at age 65} & 18,000 & 39,000 & 84,000 \\
\hline & \multicolumn{3}{|c|}{ Semi-personalized portfolio } \\
\hline \multicolumn{4}{|c|}{ CRRA assumed to be 5 but really 2} \\
\hline Percent of salary & 0.25 & 0.33 & 0.46 \\
\hline Dollars at age 65 & 9,000 & 25,000 & 70,000 \\
\hline \multicolumn{4}{|c|}{ CRRA assumed to be 2 but really 5} \\
\hline Percent of salary & 0.49 & 0.51 & 0.54 \\
\hline Dollars at age 65 & 19,000 & 39,000 & 82,000 \\
\hline
\end{tabular}

Source: Authors' calculations. 
Table 3. Results of Econometric Models with Spousal Labor Force Participation, Spousal Earnings, and Household Financial Assets Exclusive of the Participant's 401(k) Plan Balance as the Dependent Variable

\begin{tabular}{|c|c|c|c|c|c|c|}
\hline & \multicolumn{2}{|c|}{$\begin{array}{c}\text { Probit model, } \\
\text { spousal labor force participation }\end{array}$} & \multicolumn{2}{|c|}{ OLS model, log spousal earnings } & \multicolumn{2}{|c|}{ OLS model, log financial assets } \\
\hline & Marginal effect & Standard error & Coefficient & Standard error & Coefficient & Standard error \\
\hline \multicolumn{7}{|l|}{ Male participant } \\
\hline $100 *$ Age $^{2}$ & 0.022 & 0.096 & 0.147 & 0.164 & $0.535^{* *}$ & 0.211 \\
\hline $10000 *$ Age $^{3}$ & -0.025 & 0.072 & -0.113 & 0.126 & $-0.453 * * *$ & 0.161 \\
\hline $100 *$ Tenure $^{2}$ & $-0.023^{* * *}$ & 0.008 & -0.024 & 0.020 & 0.027 & 0.020 \\
\hline \multicolumn{7}{|l|}{ Education } \\
\hline Less than high school & $-0.162^{* * *}$ & 0.043 & $-0.117^{* *}$ & 0.047 & $-0.366^{* * *}$ & 0.118 \\
\hline Some college & $0.099 * * *$ & 0.021 & $0.104^{* * *}$ & 0.035 & $0.221^{* * *}$ & 0.049 \\
\hline Log participant plan balance & 0.001 & 0.004 & $-0.025^{* *}$ & 0.012 & $0.185^{* * *}$ & 0.016 \\
\hline Age & $0.068^{* *}$ & 0.029 & 0.070 & 0.068 & $0.289^{* * *}$ & 0.105 \\
\hline $100 *$ Age $^{2}$ & $-0.173^{* * *}$ & 0.066 & -0.021 & 0.173 & $-0.539^{* *}$ & 0.251 \\
\hline $10000 *$ Age $^{3}$ & $0.130^{* * *}$ & 0.050 & -0.065 & 0.142 & $0.414^{* *}$ & 0.192 \\
\hline Tenure in years & $-0.016^{* * *}$ & 0.002 & $-0.013^{*}$ & 0.008 & -0.010 & 0.012 \\
\hline $100 *$ Tenure $^{2}$ & $0.053^{* * *}$ & 0.009 & 0.006 & 0.026 & 0.026 & 0.036 \\
\hline \multicolumn{7}{|l|}{ Education } \\
\hline Less than high school & 0.023 & 0.028 & $-0.118^{* *}$ & 0.055 & $-0.662^{* * *}$ & 0.152 \\
\hline Some college & $0.055^{* * *}$ & 0.017 & $0.231^{* * *}$ & 0.035 & $0.509^{* * *}$ & 0.073 \\
\hline
\end{tabular}


Table 3. Results of Econometric Models with Spousal Labor Force Participation, Spousal Earnings, and Household Financial Assets Exclusive of the Participant's 401(k) Plan Balance as the Dependent Variable (cont'd)

\begin{tabular}{|c|c|c|c|c|c|c|}
\hline & \multicolumn{2}{|c|}{$\begin{array}{c}\text { Probit model, } \\
\text { spousal labor force participation }\end{array}$} & \multicolumn{2}{|c|}{ OLS model, log spousal earnings } & \multicolumn{2}{|c|}{ OLS model, log financial assets } \\
\hline Log participant plan balance & -0.0002 & 0.008 & $0.022 * * *$ & 0.006 & $0.156^{* * *}$ & 0.016 \\
\hline Constant & & & 6.269 & 0.996 & -4.204 & 1.646 \\
\hline R squared & 0.093 & & 0.143 & & 0.483 & \\
\hline
\end{tabular}

Notes: Sample includes 4,936 married men and 3,315 married women in the Survey of Consumer Finances who were aged 22-64 in 2010 and who contributed to a 401(k) plan. Of these, 2,926 and 2,642 reported that their spouse was working for pay. SCF sample weights used. One, two, and three stars denote that the coefficient differs from zero at the ten, five, and one percent significance levels.

Source: Authors' calculations. 
Table 4. Costs of Misclassifying Spousal Labor Force Participation and Misestimating Earnings

Percent of salary Dollars at age 65

Married men

Single earner - misclassified as two earner

0.25

14,000

Two earner - misclassified as one earner

0.41

31,000

Two earner - wife's earnings overstated by 16.2 percent

0.40

30,000

Two earner - wife's earnings understated by 18.8 percent

0.40

30,000

Notes: It is assumed that the household is an average one or two earner household, as appropriate, and is placed in the semi-personalized portfolio.

Source: Authors' calculations. 
Table 5. Compensation Required for Adopting a Semi-Personalized Portfolio Based on Household Income, by Earnings and Degree of Earnings Uncertainty

\begin{tabular}{|c|c|c|c|}
\hline & \multicolumn{3}{|c|}{ Income } \\
\hline & Low & Average & High \\
\hline & \multicolumn{3}{|c|}{ Low volatility } \\
\hline \multicolumn{4}{|l|}{ CRRA $=2$} \\
\hline Percent of salary & 0.03 & 0.05 & 0.05 \\
\hline Dollars at age 65 & 1,000 & 4,000 & 8,000 \\
\hline \multicolumn{4}{|l|}{$\mathrm{CRRA}=5$} \\
\hline Percent of salary & 0.04 & 0.01 & 0.01 \\
\hline \multirow[t]{2}{*}{ Dollars at age 65} & 1,000 & 1,000 & 2,000 \\
\hline & \multicolumn{3}{|c|}{ Average volatility } \\
\hline \multicolumn{4}{|l|}{ CRRA = 2} \\
\hline Percent of salary & 0.00 & 0.00 & 0.00 \\
\hline Dollars at age 65 & 0 & 0 & 0 \\
\hline \multicolumn{4}{|l|}{$\mathrm{CRRA}=5$} \\
\hline Percent of salary & 0.00 & 0.00 & 0.00 \\
\hline \multirow{2}{*}{ Dollars at age 65} & 0 & 0 & 0 \\
\hline & \multicolumn{3}{|c|}{ High volatility } \\
\hline \multicolumn{4}{|l|}{$\mathrm{CRRA}=2$} \\
\hline Percent of salary & .055 & 0.51 & 0.49 \\
\hline Dollars at age 65 & 21,000 & 39,000 & 74,000 \\
\hline \multicolumn{4}{|l|}{$\mathrm{CRRA}=5$} \\
\hline Percent of salary & 2.12 & 2.35 & 2.15 \\
\hline Dollars at age 65 & 78,000 & 179,000 & 327,000 \\
\hline \multicolumn{4}{|c|}{$\begin{array}{l}\text { Notes: The standard deviation of the earnings shocks of the low- } \\
\text { volatility household is assumed to be zero, and that of the high- } \\
\text { volatility household is twice the average. }\end{array}$} \\
\hline
\end{tabular}




\section{RECENT WORKING PAPERS FROM THE CENTER FOR RETIREMENT RESEARCH AT BOSTON COLLEGE}

Job Demand and Early Retirement

Sepideh Modrek and Mark R. Cullen, August 2012

Changes in Labor Force Participation of Older Americans and Their Pension Structures: A Policy Perspective

Frank W. Heiland and Zhe Li, July 2012

How Would GASB Proposals Affect State and Local Pension Reporting?

Alicia H. Munnell, Jean-Pierre Aubry, Joshua Hurwitz and Laura Quinby, June 2012

Borrow Less Tomorrow: Behavioral Approaches to Debt Reduction

Dean Karlan and Jonathan Zinman, May 2012

Spousal Labor Market Effects from Government Health Insurance: Evidence from A Veterans Affairs Expansion

Melissa A. Boyle and Joanna N. Lahey, April 2012

Measuring Social Security Proposals by More than Solvency: Impacts on Poverty, Progressivity, Horizontal Equity, and Work Incentives

Melissa M. Favreault and C. Eugene Steuerle, April 2012

How Important Is Asset Allocation to Financial Security in Retirement?

Alicia H. Munnell, Natalia Sergeyevna Orlova, and Anthony Webb, April 2012

Great Recession-Induced Early Claimers: Who Are They? How Much Do They Lose?

Matthew S. Rutledge and Norma B. Coe, April 2012

Effects of Employer Health Costs on the Trend and Distribution of Social Security-Taxable Wages

Gary Burtless And Sveta Milusheva, April 2012

Should Households Base Asset Decumulation Strategies on Required Minimum Distribution Tables?

Wei Sun and Anthony Webb, April 2012

Geographic Mobility Among Residents in Seniors Housing and Care Communities: Evidence from the Residents Financial Survey

Norma B. Coe and April Yanyuan Wu, April 2012

All working papers are available on the Center for Retirement Research website (http://crr.bc.edu) and can be requested by e-mail (crr@bc.edu) or phone (617-552-1762). 